\title{
Gestión de mercados en el destino Holguín para favorecer un desarrollo turístico sostenible
}

\author{
Market management in the Holguín destination to promote sustainable \\ tourism development \\ MSc. Justa Ramona Medina Labrada. ${ }^{1}$, MSc. Merlinda Clarke Bloomfield. ${ }^{2}$ \& Lic. \\ Elizabeth del Carmen Pérez Ricardo. ${ }^{3}$
}

\begin{abstract}
Efficient management of tourist markets in a destination proves an essential element in getting satisfactory and growing outcomes for its sustainable development; therefore, organization and destination managers should constantly assess and improve managing practices. Holguin, as a tourist destination, strongly depends on a restricted number of source markets; consequently, management actions are required to achieve both diversification and consolidation of markets with positive repercussion on sustainable management in the territory. Hence, this research aims at assessing tourist market management in Holguin destination as well as proposing strategies to favor its development. As literature review did not reveal any appropriate procedure in relation to the above-mentioned objectives, a new one is proposed. This proposition, by using appropriate methods and techniques for every step, involves the analysis of present structure of markets, the assessment of competition market share, a thorough characterization of markets, the devising of potential sceneries for the chosen markets as well as proposal of strategies in addition to general actions and recommendations. As a result, a set of strategies and actions in relation to the three main markets plus a group of general recommendations aimed at improving source market management in Holguin destination were proposed in order to contribute to sustainable development.
\end{abstract}

Key Words: Tourist Market Management, Holguin Tourist Destination, Sustainable Tourist Development.

\section{Resumen}

La gestión eficaz de los mercados en un destino turístico es indispensable y básico para obtener resultados satisfactorios y crecientes en el desarrollo sostenible del mismo, por lo

\footnotetext{
1 jmedina@uho.edu.cu

3 elizabeth.ricardo@uho.edu.cu
} 
que los gestores de organizaciones y destinos deben evaluar y mejorar permanentemente la gestión de sus mercados. El destino turístico Holguín posee una marcada dependencia de un pequeño número de mercados, requiriéndose encaminar acciones para gestionar con efectividad cada uno y el conjunto de ellos, de manera que se consoliden y diversifiquen los mismos y se favorezca la gestión sostenible del turismo en el territorio, por lo cual la investigación se planteó el objetivo de evaluar la gestión de los mercados del destino Holguín y proponer estrategias para favorecer su desarrollo. Al no encontrar en la literatura revisada ningún procedimiento adecuado para los fines de la presente investigación, se propuso uno nuevo. El mismo abarca el análisis de la estructura de mercados actual, la evaluación de la cuota de los mercados de los competidores, la caracterización amplia de los mercados, la elaboración de escenarios para los mercados seleccionados y la propuesta de estrategias, acciones y recomendaciones generales, a partir de la utilización de métodos y técnicas convenientes para cada paso. Como resultado se propusieron un conjunto de estrategias y acciones para los tres mercados principales y un grupo de recomendaciones generales para mejorar la gestión de mercados en el destino Holguín y contribuir a su desarrollo sostenible.

Palabras Clave: Gestión de Mercados Turísticos, Destino Holguín, Desarrollo Turístico Sostenible.

\section{Introducción}

Los resultados del turismo en el mundo en 2018 superaron las previsiones realizadas por la OMT y su desarrollo estuvo condicionado por un conjunto de factores entre los que destacan: entorno económico favorable, fuerte demanda de los principales mercados emisores, consolidación de la recuperación en destinos principales afectados por crisis previas, mejor conectividad aérea y mayor facilitación de visados (OMT, 2019).

De acuerdo a datos revelados por (Pololikashvili, 2020), actual secretario general de la OMT, en la presentación del Barómetro 2020, en el año 2019 se registraron 1.500 millones de llegadas de turistas internacionales en el mundo y se espera que este incremento del $4 \%$ con respecto al año anterior se repita en el 2020, lo que confirma la posición del turismo como un sector económico pujante y resistente, especialmente teniendo en cuenta las actuales incertidumbres. Dada la posición del turismo como uno de los primeros sectores de exportación y creación de empleo, la OMT defiende la necesidad de un crecimiento responsable y, considerando que el turismo ocupa un lugar primordial en las políticas mundiales de desarrollo, puede aún alcanzar un mayor reconocimiento político e incidir de manera efectiva en este decenio de acción, con solo diez años por delante para alcanzar la Agenda 2030 y sus 17 Objetivos de Desarrollo Sostenible.

Las proyecciones realizadas por la propia OMT indican que el turismo tendrá un crecimiento global sostenido, que se estima alcance los 1,8 billones de llegadas de turistas internacionales en 2030 y esta cifra se lograría principalmente por el crecimiento de los países emergentes (China e India, entre ellos). En consecuencia, el flujo de llegadas de los turistas internacionales de las economías emergentes (Rusia y Brasil, además de los 
antes mencionados) superaría al tradicionalmente flujo mayoritario de turistas provenientes de economías desarrolladas, lo que invertiría el comportamiento actual (Osorio García, Ramírez de la O, \& Viesca González, 2018).

Para aprovechar estas oportunidades de crecimiento, los destinos turísticos deben evaluar permanentemente la gestión de los mercados como premisa básica en las decisiones que adopten y en consecuencia obtener cada año el mayor nivel de ocupación posible y los mayores beneficios económicos.

Por otra parte, el desarrollo sostenible incluye los aspectos medioambiental, sociocultural y económico, habiéndose de establecer un equilibrio adecuado entre esas tres dimensiones para garantizar la sostenibilidad a largo plazo. En esta tercera dimensión se afianza la idea de que para obtener esos resultados económicos viables a largo plazo es indispensable realizar una buena gestión de los mercados y segmentos actuales y potenciales para asegurar a los destinos y organizaciones flujos turísticos que permitan incrementar la operación y, en consecuencia, la sostenibilidad de los mismos.

La (OMT, 2019) define el turismo sostenible como aquel que pretende satisfacer las necesidades de los turistas, así como de los destinos turísticos protegiendo e incrementando las oportunidades a futuro. Es decir, gestionar los recursos de manera que las necesidades económicas, sociales y estéticas puedan ser satisfechas mientras se mantiene la identidad cultural, los procesos ecológicos esenciales, la diversidad biológica y los sistemas de vida. Hay que recordar que el desarrollo turístico sostenible apunta a minimizar los daños ambientales y culturales, optimizar la satisfacción del visitante y maximizar el desarrollo económico a largo plazo de la región en cuestión.

La propia fuente destaca que la OMT menciona que la sostenibilidad está ligada a tres hechos importantes: calidad, continuidad y equilibrio. Por lo tanto, el turismo sostenible es un modelo de desarrollo económico diseñado para mejorar la calidad de vida de la población local, la gente que trabaja y vive en el destino turístico, proveer mayor calidad de las experiencias para los visitantes, mantener la calidad del medio ambiente de la cual depende tanto la población local como los visitantes, la consecución de mayores niveles de rentabilidad económica de la actividad turística para los residentes locales y asegurar la obtención de beneficios por parte de los empresarios turísticos (Monge \& Perales, 2016).

De acuerdo a (UNEP \& UNWTO, 2005) las directrices para el desarrollo sostenible del turismo y las prácticas de gestión sostenible se aplican a todas las formas de turismo en todos los tipos de destinos, incluidos el turismo de masas y los diversos segmentos turísticos. Los principios de sostenibilidad se refieren a los aspectos medioambiental, económico y sociocultural del desarrollo turístico, habiéndose de establecer un equilibrio adecuado entre esas tres dimensiones para garantizar su sostenibilidad a largo plazo. Por lo tanto, el turismo sostenible debe:

- Dar un uso óptimo a los recursos medioambientales, que son un elemento fundamental del desarrollo turístico, manteniendo los procesos ecológicos esenciales y ayudando a conservar los recursos naturales y la diversidad biológica. 
- Respetar la autenticidad sociocultural de las comunidades anfitrionas, conservar sus activos culturales y arquitectónicos y sus valores tradicionales, y contribuir al entendimiento y la tolerancia intercultural.

- Asegurar unas actividades económicas viables a largo plazo, que reporten a todos los agentes unos beneficios socioeconómicos bien distribuidos, entre los que se cuenten oportunidades de empleo estable y de obtención de ingresos y servicios sociales para las comunidades anfitrionas, y que contribuyan a la reducción de la pobreza.

En la literatura revisada sobre gestión de mercados turísticos se pudo apreciar que es escasa la producción científica en ese tema. (López-Bonilla \& López, 2015) plantean que existen muchos libros y manuales publicados sobre investigación de mercados, pero a pesar de ello todavía es muy escasa la perspectiva de investigación de mercados en este ámbito, al menos en España y en los países hispanoamericanos.

Así mismo (Hernández-Martín, 2006) esboza que el turismo es una actividad singular desde la perspectiva de la demanda, pues se relaciona con el consumo que se realiza fuera del entorno habitual en el que reside y trabaja una persona y por otra parte, la singularidad de los mercados turísticos se relaciona también con las formas de comercialización puesto que, por definición, oferentes y demandantes residen en lugares diferentes y de ahí el papel de los intermediarios, así como las posibilidades de contacto directo a través de las tecnologías de la información y las comunicaciones. Otra de las características de los mercados turísticos es que no pueden entenderse al margen de los recursos de atracción en el destino. Todo ello demuestra la complejidad y necesidad de la evaluación de la gestión de mercados turísticos.

El destino turístico Holguín ha mantenido en los últimos años una estructura de mercados caracterizada por la dependencia del mercado canadiense, fundamentalmente. Inglaterra y Alemania, que son dos de los mercados principales, no tienen un comportamiento favorable, ya que el primero de ellos disminuye sostenidamente su participación y Alemania tiene un desempeño irregular. El mercado nacional incrementa su aportación de clientes cada año y ocupa actualmente el tercer lugar en el destino. Aunque en los dos últimos años analizados Rusia y Estados Unidos han ganado en cuota de mercado, no se logra la diversificación de mercados necesaria.

Estos elementos evidencian la necesidad de realizar un análisis de la gestión de mercados en el destino, por lo que el objetivo del trabajo fue evaluar los mercados del destino Holguín y proponer estrategias para favorecer su gestión y el desarrollo turístico sostenible del territorio.

\section{Metodología}

Al no encontrar en la literatura revisada ningún procedimiento que se adaptara a los objetivos de la investigación se propuso uno nuevo, con la finalidad adicional de que el mismo pudiera ser utilizado por gestores turísticos e investigadores y donde se aplicaran 
las técnicas de investigación científicas adecuadas para asegurar un resultado fiable. El mismo se describe, de forma sintética, a continuación.

Procedimiento para evaluar y proyectar la gestión de mercados en un destino turístico Objetivo del procedimiento: Disponer de una herramienta científica para la evaluación y proyección de la gestión de mercados en un destino turístico.

Paso1: Evaluación de la estructura de mercados del destino en estudio

Descripción: Se debe cuantificar la cuota de cada mercado en el destino en los últimos años, para evaluar la estructura de mercados del mismo, precisando la participación e importancia de los principales mercados.

Técnicas y métodos a utilizar: Análisis documental, procesador de datos Microsoft Office Excel.

Paso 2: Evaluación de la cuota de los mercados en estudio en relación con la cuota de los principales competidores

Descripción: Se realizará un análisis de la evolución de la cuota de mercados en los principales destinos competidores, en comparación con la cuota de mercados del destino en estudio; así como los principales factores del entorno que determinan dicho comportamiento.

Técnicas y métodos a utilizar: Análisis documental, Procesador de datos Microsoft Office Excel.

Paso 3: Caracterización de los mercados del destino en estudio

Descripción: Se caracterizará cada mercado lo más ampliamente posible, de manera que permita identificar todas las variables cuantitativas, cualitativas, internas y externas que inciden en la evolución del mismo, las que mediante el método de reducción de listado se deben llevar a un número que pueda ser manejable en el estudio (no sobrepasar las 25 variables).

Técnicas y métodos a utilizar: Encuestas, entrevistas, búsqueda de información secundaria, método de reducción de listados.

Paso 4: Determinación de las variables clave que inciden en el comportamiento de cada mercado en estudio

Descripción: Para la construcción de la base a utilizar en los softwares se delimita el sistema en su entorno, a partir de la caracterización del mercado y se determinan las variables que inciden en este. Luego se reducen las variables mediante la utilización del criterio de especialistas (se recomienda entre 15 y 20), las que servirán de base para determinar las variables clave, mediante el uso del software MICMAC. Las mismas se someten a análisis según su posicionamiento en los planos de influencia y dependencia directa e indirecta, tomando como variables clave las ubicadas en los cuadrantes 1 y 2 del 
plano de influencia indirecta. Luego se asocian a cada variable los actores que determinan la incidencia o no de la variable en el mercado.

Técnicas y métodos a utilizar: Método de análisis estratégico mediante el software MICMAC, criterio de especialistas.

Paso 5: Elaboración de los escenarios para proyectar la gestión de los mercados seleccionados para el estudio

Descripción: En este paso se descompone el sistema (mercados emisores) en subsistemas (variables económicas, políticas, naturales, tecnológicas, sociales, etc.) para obtener, mediante el uso del método de Análisis Morfológico, el espacio morfológico útil o probable a través del software MORPHOL, asignando a cada variable clave tres hipótesis, de las cuales se seleccionan, mediante la encuesta Delphi, aquellas con mayor probabilidad de ocurrencia para el mercado objeto de estudio y mediante el software SMIC-PROB-EXPERT se obtienen las combinaciones de hipótesis con mayor probabilidad de ocurrencia (el software arroja todas las combinaciones posibles de hipótesis) a partir de las cuales se redactarán los escenarios.

Esto sirve de base al proceso de tomas de decisiones, por lo que los decisores junto a los investigadores seleccionarán tres hipótesis: una con alta probabilidad de ocurrencia, una con media probabilidad de ocurrencia y una tercera con probabilidad de ocurrencia baja. Técnicas y métodos a utilizar: Análisis morfológico mediante el software MORPHOL y Probabilización de escenarios mediante el software SMIC-PROB-EXPERT.

Paso 6: Propuesta de estrategia y acciones para mejorar la gestión en cada mercado Descripción: A partir del escenario seleccionado y para un horizonte de mediano y largo plazo se formulan por los decisores de conjunto con los investigadores las estrategias y acciones para cada mercado con sus responsables y fechas de cumplimiento, con el objetivo de mejorar la gestión del destino en el mercado.

Técnicas y métodos a utilizar: Método de multicriterios y políticas mediante el software MULTIPOL, técnicas de consenso.

Paso 7: Propuesta de recomendaciones generales para favorecer la gestión sostenible de los mercados en el destino

Descripción: Una vez propuestas las estrategias y acciones por mercado para la mejora de la gestión y resultados en cada mercado, se proponen generalizaciones o recomendaciones generales válidas para el conjunto de los mercados, lo que puede contribuir a la efectividad y sostenibilidad de la gestión de mercados en el destino.

Técnicas y métodos a utilizar: Técnicas de consenso.

\section{Resultados y discusión}

Como resultado de la aplicación del procedimiento en el destino Holguín se obtuvieron los resultados siguientes.

Paso 1. Evaluación de la estructura de mercados del destino Holguín 
La información que aporta el gráfico No. 1 permite corroborar que el destino Holguín posee una importante dependencia del mercado canadiense. Por otra parte, otros mercados importantes como Inglaterra y Alemania poseen decrecimiento sostenido en el primero de ellos e irregularidad en su comportamiento en el segundo caso. El mercado cubano gana en cuota de participación y se incorporan otros como Rusia y Estados Unidos en 2017 y 2018. Este último con previsiones de decrecimiento por la política hostil del Gobierno Estadounidense hacia Cuba. A pesar de todo esto es evidente que se requiere mejorar la estructura de mercados del destino.

Gráfico 1: Estructura de mercados del destino turístico Holguín 2015 - 2018
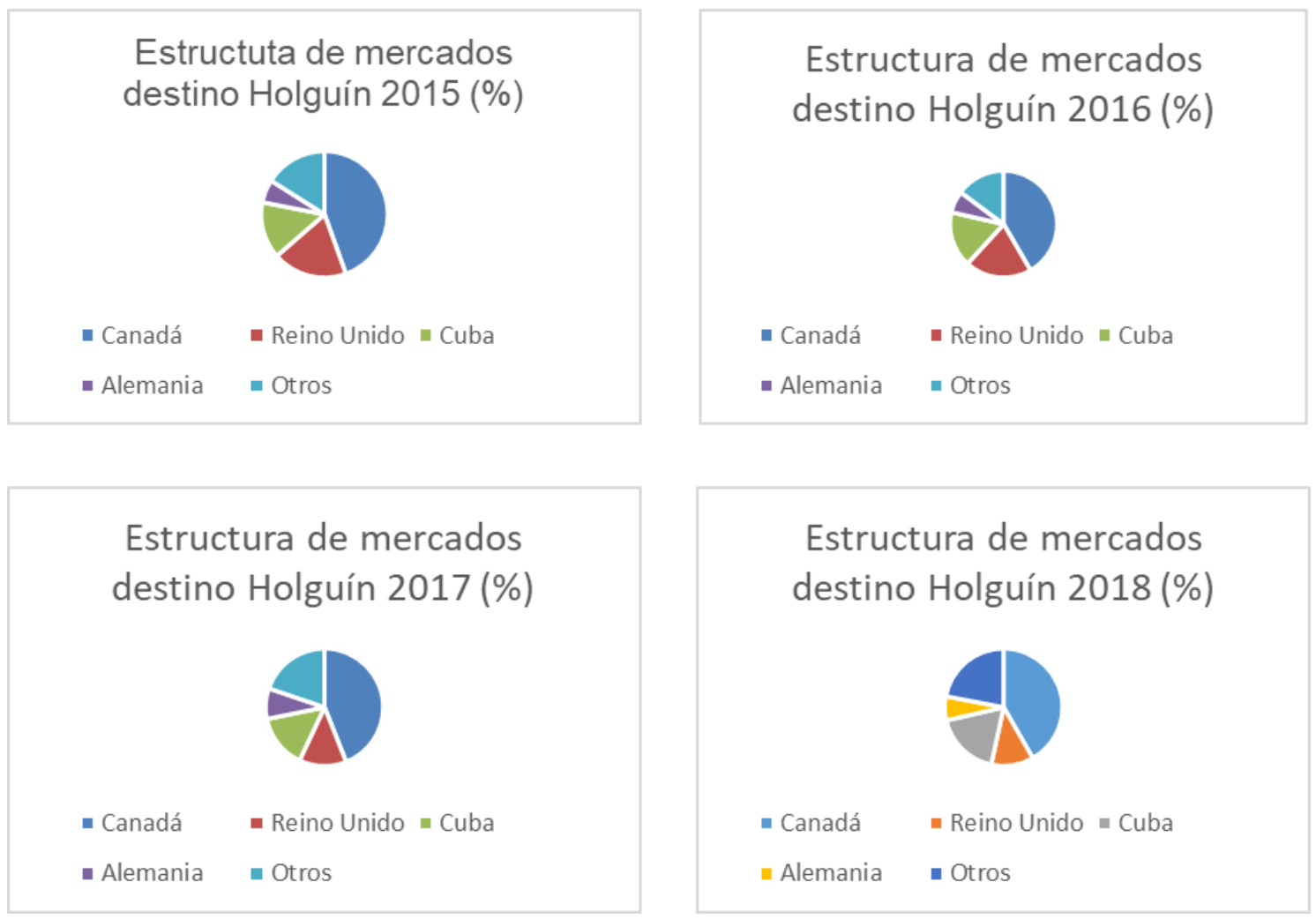

Fuente: Elaboración propia a partir de (ONEI, 2016, 2017, 2018, 2019)

Paso 2: evaluación de la cuota de los mercados en estudio en relación con la cuota de los principales competidores

Como no fue posible disponer de datos de los destinos competidores directos de Holguín en el Caribe se realizó un análisis de los competidores principales de Cuba en el área. Como se aprecia en los gráficos 2 y 3 las cuotas de los mercados Canadá e Inglaterra se mantienen similares para los tres países destino en el período analizado.

Gráfico 2: Flujo de clientes canadienses a los principales destinos del Caribe en el período 2015 - 2018. 
Flujo de clientes canadienses a los principales destinos del Caribe

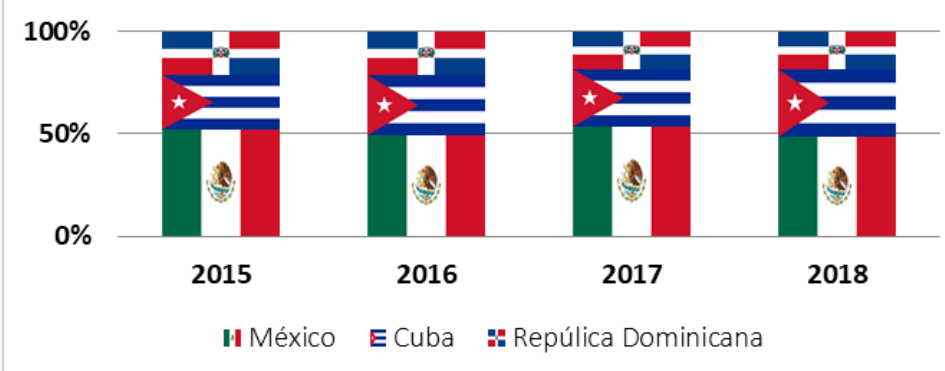

Fuente: Elaboración propia a partir de ONEI Cuba, DATATUR México y ANALYTICA República Dominicana

Gráfico 3: Flujo de clientes ingleses a los principales destinos del Caribe en el período $2015-2018$.

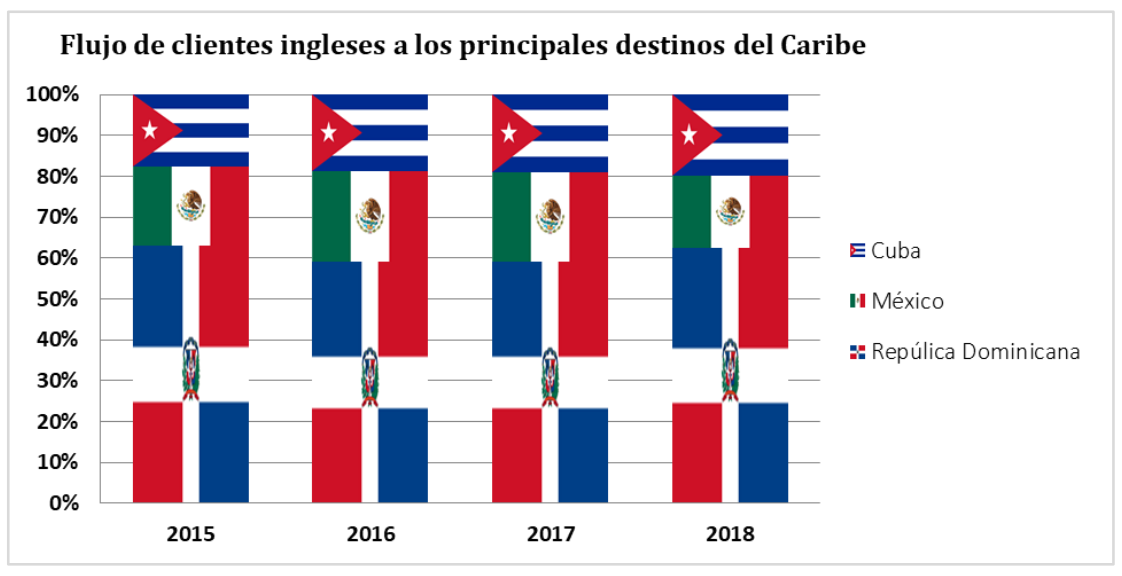

Fuente: Elaboración propia a partir de ONEI Cuba, DATATUR México y ANALYTICA República Dominicana

\section{Paso 3. Caracterización de los principales mercados del destino Holguín}

En el paso 1 se precisaron los principales mercados del destino. A continuación, se refleja de forma resumida la caracterización de los mismos, que se realizó a partir de la aplicación de una encuesta a una muestra representativa de clientes de cada uno de ellos en el período febrero - abril de 2019, entrevistas a informantes clave y análisis de documentos elaborados por organizaciones diversas.

\section{Canadá}

Cuba es uno de los destinos internacionales preferido de los canadienses. Por su parte, Canadá constituye la mayor fuente de turistas para Cuba. En 2017 los mayores flujos turísticos de Canadá fueron hacia: Estados Unidos, México, Cuba, Francia y República Dominicana y las principales regiones emisoras fueron: Toronto, Montreal, Vancouver, 
Ottawa, Calgary. Edmonton, Quebec. Ontario y Hamilton (EOEI, 2018). Entre ciudades canadienses y Holguín hay ocho vuelos semanales como promedio.

De los clientes encuestados el 54.02\% refiere que se informa para seleccionar el destino a través de amigos y familiares, mientras que el $41.38 \%$ utiliza Tripadvisor y el $24.14 \%$ a través de sitios web de turoperadores. Las recomendaciones sobre el destino del viaje más valoradas provienen de amigos y familiares, seguido de las redes sociales y sitios de comentarios de viajeros.

En cuanto a las vías utilizadas para efectuar las reservas el $50.57 \%$ las realizan por las oficinas de agencias de viajes emisoras, el $31.03 \%$ en sitios web de agencias de viajes cubanas y el $13.79 \%$ mediante los sitios web de los hoteles. El resto las realizan a través de sitios web de turoperadores.

El principal motivo de viaje de los clientes canadienses es relajarse con un $65.5 \%$; sin embargo, también refirieron como motivos de viajes: conocer nuevas culturas $30.6 \%$, y encontrarse con la naturaleza $3.9 \%$.

La actividad preferida de los clientes canadienses es el disfrute del sol y la playa con un $71.26 \%$; sin embargo, los clientes encuestados refirieron preferencias adicionales como: pasear en catamarán $35.63 \%$; asistir a espectáculos culturales diversos $25.29 \%$; disfrutar de cabarets $20.69 \%$; bucear en aguas abiertas $17.24 \%$; caminar por la cuidad $16.09 \%$; disfrutar de comida típica campesina $13.79 \%$ y visitar lugares históricos $12.64 \%$.

El $50.6 \%$ de los clientes encuestados prefieren alojarse en hoteles económicos, el $19.5 \%$ en las villas, el $18.4 \%$ en casas de renta y el $11.5 \%$ gustan alojarse en hoteles de alto estándar. Por otra parte, el $58.62 \%$ optan por viajar con sus parejas y el $39.08 \%$ en familia. El resto con amigos o solos.

De los clientes encuestados refirieron tener gastos entre los 701 y 1000 CUC el $35.60 \%$; entre 500 y 700 CUC un $24.10 \%$, entre 300 y 500 CUC el $18.4 \%$, con gastos mayores a 1000 CUC el $13.8 \%$ y entre 100 y 300 un $8,1 \%$.

Sus hábitos alimentarios se caracterizan por el limitado contenido de grasa en las comidas, bajo contenido en salsas, cenas tempranas, gustan de los mariscos, de sopas en la cena, alimentos sazonados con mostaza, ajo puerro, pimienta y apio, vegetales poco cocinados. No le agrada el consumo de vísceras. Dentro de las bebidas prefieren las cervezas y el ron cubano.

\section{Reino unido}

Reino Unido es uno de los principales emisores del mundo. Las principales ciudades emisoras son: Manchester, New Castle, Leeds y Carwel, Reading y Northampthonshire. Entre los destinos más visitados por los británicos se destacan España, Francia, Estados Unidos, Turquía, así como otros destinos de la zona del Mar Mediterráneo y el Caribe, principalmente República Dominicana, México y Cuba. Los sitios cubanos más visitados son La Habana, seguida por Holguín, Cayo Coco, Cayo Santa María y Varadero. 
La estacionalidad de este mercado es muy marcada en la temporada de verano, puesto que es una costumbre en muchos británicos tomar las vacaciones para viajar en dicha temporada, aunque es bueno señalar que presenta un buen comportamiento durante los meses de enero a marzo en el destino Cuba, mientras que en Holguín se concentran fundamentalmente entre los meses de mayo a agosto.

El $49 \%$ de los encuestados utilizan los turoperadores para informarse y seleccionar el destino de viaje, un $39 \%$ utiliza las redes sociales (principalmente Facebook) y un $12 \%$ lo hace a través de TripAdvisor. Los clientes en su mayoría reservan sus viajes a través de oficinas de agencias de viajes en su país de procedencia.

Un $49 \%$ de los turistas encuestados en Holguín refiere que viajan con el objetivo principal de relajarse, un $38 \%$ manifiesta que su motivo fundamental es el conocimiento de nuevas culturas y un $12 \%$ define su preferencia por el disfrute de la naturaleza. Entre las actividades que prefieren realizar en el destino sobresale el intercambio con pobladores de la localidad, el disfrute de la playa y de la comida criolla y tradiciones culinarias cubanas.

De acuerdo a los resultados de la encuesta aplicada, la mayoría de los ingleses escogen los hoteles económicos para alojarse y viajan por recomendación de amigos y familia, así como de redes sociales.

\section{Cuba}

A partir de las encuestas aplicadas se pudo conocer que los clientes que más visitan el destino Holguín son los provenientes de la propia provincia y de Granma. Aunque en menor medida, también acuden personas del resto de las provincias orientales: Las Tunas, Santiago de Cuba y Guantánamo.

Aunque tienen preferencia por diversas actividades durante sus viajes, las principales son: disfrutar de la playa, pasear en catamarán, disfrutar de cabarets, recorrer senderos naturales, y disfrutar de comida típica campesina.

Los flujos turísticos pertenecientes al mercado nacional se generan todo el año, sin embargo, estos se incrementan notablemente en el período vacacional comprendido en los meses de julio y agosto y, aunque en menor medida, en las semanas de receso docente.

El $56.25 \%$ de los turistas encuestados se informan a través de amigos y familiares, el 25 $\%$ se informan mediante Airbnb y el $18.75 \%$ lo hacen a través del sitio web del hotel, Facebook o YouTube. Sin embargo, el $69.12 \%$ realiza su reserva del viaje a través de las oficinas de agencias de viaje del país, el $27.75 \%$ reserva a través de los sitios web de las agencias de viaje cubanas y solo el $3.13 \%$ realizan su reserva mediante el sitio web del hotel.

El $53.13 \%$ de los turistas nacionales eligen alojarse en un hotel económico, el $18.75 \%$ prefieren alojarse en villas, el $6.25 \%$ lo hace en casas de renta y el $21.87 \%$ opta por un hotel de alto estándar en el destino, que en algunos casos incluye a los hoteles cuatro estrellas. El $90.63 \%$ de los clientes gastan entre 100 y 300 CUC, el $6.25 \%$ entre 301 y 500 CUC, y el $3.12 \%$ gastan entre 701 y 1000 CUC. 
Los turistas nacionales realizan sus viajes con un promedio de tres días (tres días y dos noches). El $56.25 \%$ prefiere viajar en familia, el $36.88 \%$ opta por hacerlo en pareja, el resto con amigos o solos.

\section{Paso 4. Determinación de las variables clave que inciden en la evolución de cada mercado}

Como resultado de aplicar las técnicas y métodos descritos en el paso 3 del procedimiento se determinaron las variables clave que inciden en cada mercado escogido y que se reflejan a continuación.

Variables clave para el mercado de Canadá

1. Definir motivo principal del viaje y beneficios buscados por los distintos segmentos de mercado

2. Actividades que les gusta realizar a los turistas en el destino

3. Vinculación aérea, terrestre o marítima directa entre el destino receptor y el destino emisor

4. Principales turoperadores del país emisor, caracterización de los mismos y operaciones actuales con el receptor

5. Etapas del año de mayores flujos turísticos dentro y fuera del país de origen

6. Movilidad geográfica de los flujos turísticos.

Variables clave para el mercado de Reino Unido

1. Definir motivo principal de viaje y beneficio buscados por los distintos segmentos de mercado

2. Actividades que les gusta realizar a los turistas durante su viaje

3. Movilidad geográfica de los flujos turísticos

4. Vinculación aérea, terrestre o marítima directa entre emisor y receptor

5. Uso de internet y de las nuevas tecnologías para informarse y seleccionar el destino de viaje

6. Costo de transporte en todas sus modalidades para llegar al destino receptor

7. Gastos turísticos generales y promedio de los segmentos que componen los flujos turísticos

8. Relaciones políticas entre el país emisor y receptor

9. Principales turoperadores del país emisor.

Variables clave para el mercado de Cuba

1. Definir motivo principal del viaje y beneficios buscados por los distintos segmentos del mercado

2. Actividades que les gusta realizar a los turistas durante sus viajes

3. Grupos de referencia de mayor importancia para recomendar destinos de viajes

4. Uso de Internet y las nuevas tecnologías para informarse y seleccionar el destino del viaje. 


\section{Paso 5. Elaboración de escenarios para los mercados seleccionados}

En este paso se delimitaron para cada mercado los espacios morfológicos probables. Posteriormente se concretaron los espacios morfológicos útiles, quedando un grupo de combinaciones de hipótesis o posibles escenarios. Luego se seleccionaron las hipótesis de mayor probabilidad de ocurrencia que permiten conformar tres escenarios con alta, baja y media probabilidad, y se escogió para cada mercado el escenario medio. Los resultados se reflejan a continuación.

\section{Escenario escogido para el mercado de Canadá}

El mercado canadiense se caracteriza por una alta repitencia en el destino Holguín y una inclinación hacia el intercambio con los residentes, lo que implica que se incorpora a la motivación tradicional de sol y playa el interés por la cultura local. Esto conlleva a la necesidad de incluir mayor cantidad de actividades relacionadas con la cultura en el destino para lo cual se haría necesario la innovación y creación de infraestructuras. Dicho proceso constituiría una oportunidad para el establecimiento de relaciones con nuevos turoperadores y vinculaciones aéreas con otras zonas que generan diferentes segmentos de clientes.

\section{Escenario escogido para el mercado de Reino Unido}

Se prevé que a pesar del bloqueo económico financiero de los Estados Unidos hacia Cuba se fortalecerán las relaciones políticas entre Reino Unido y Cuba, incrementándose el arribo de turistas ingleses al destino y manteniendo la frecuencia de vuelos semanales. Sin embargo, las operaciones con turoperadores disminuirán, perderá protagonismo el deseo de relajarse como motivo principal de viaje y se mantendrá el uso de internet por parte de los turistas para informarse acerca del viaje.

\section{Escenario escogido para el mercado de Cuba}

Se prevé que en el destino Holguín, para el mercado cubano, se mantenga la relajación como principal motivo de viaje y a su vez sea el disfrute de la playa la principal actividad preferida por los turistas nacionales durante la estancia en el destino. Por otro lado, se incrementará el uso del internet y las nuevas tecnologías como vía para informarse y seleccionar el destino, también aumentará la consulta de las redes sociales como grupo de referencia para la realización del viaje; por consiguiente, es muy probable que los amigos y familiares dejen de ser el principal grupo de referencia para informarse y seleccionar el destino.

\section{Paso 6: propuesta de estrategia y acciones para mejorar la gestión en cada mercado}

A partir de la definición de los escenarios y de la selección de uno de ellos, se proponen un conjunto de estrategias y acciones para proyectar la mejora de la gestión del destino Holguín en cada mercado. Seguidamente se describen las propuestas. 
Tabla 1. Propuesta de estrategias y acciones para mejorar la gestión del destino Holguín en el mercado canadiense.

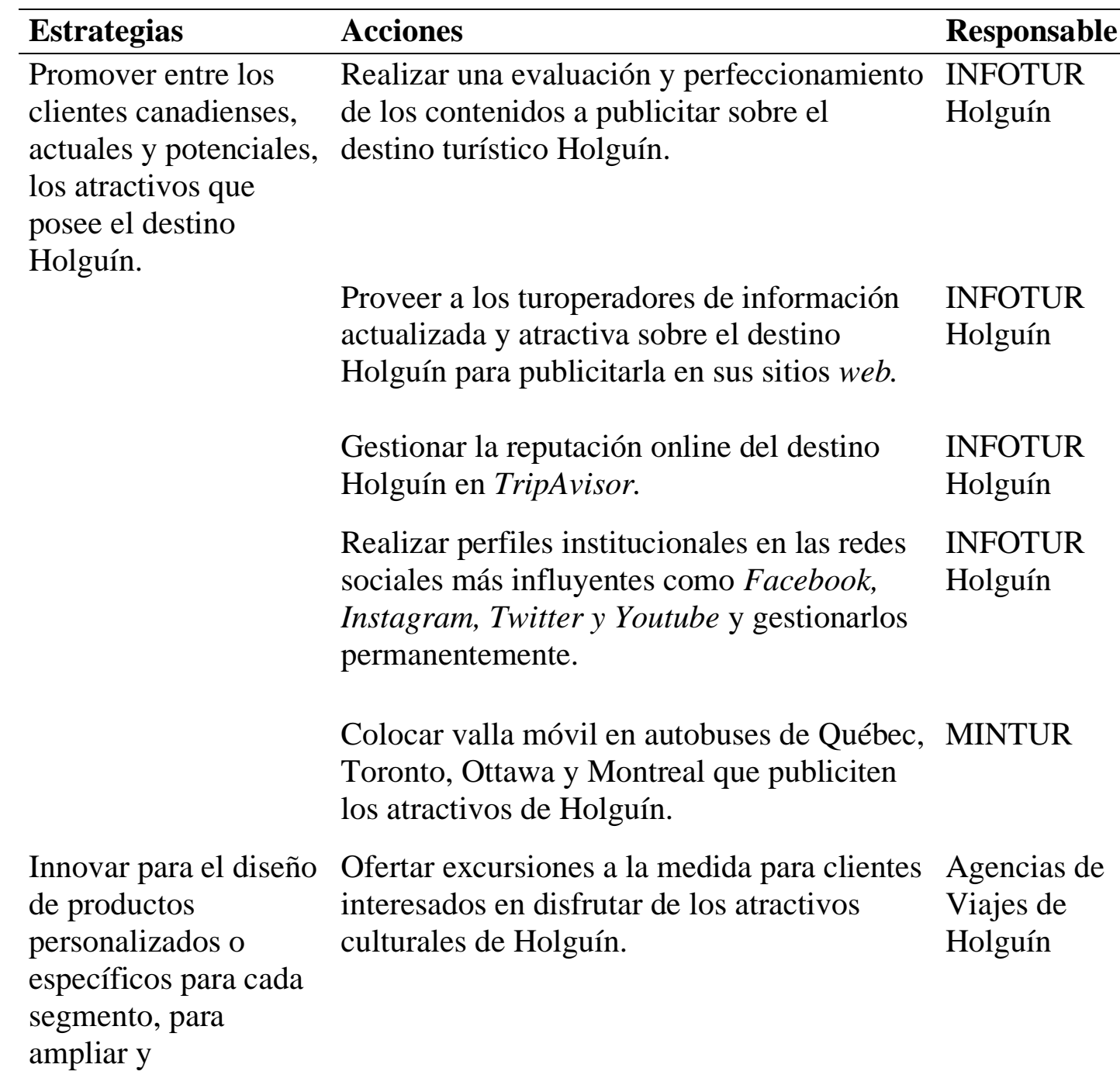

\begin{tabular}{l}
\hline Estrategias \\
\hline diversificar la cartera \\
actual de ofertas en el \\
destino, a partir de los \\
beneficios buscados \\
por los clientes.
\end{tabular}

Diseñar y ofertar excursiones que combinen sitios históricos o culturales, comida típica Agencias de cubana e intercambio con los residentes. Viajes de Holguín

Promover encuentros organizados entre Hoteles del clientes repitentes y trabajadores vinculados destino a los mismos para consolidar el impacto para los clientes de este intercambio. 
Tabla 2. Propuesta de estrategias y acciones para mejorar la gestión del destino Holguín en el mercado del Reino Unido.

\begin{tabular}{lrll}
\hline Estrategia & Acción & Responsab \\
\hline $\begin{array}{l}\text { Diversificar } \\
\text { canales }\end{array}$ & $\begin{array}{r}\text { los } \\
\text { de }\end{array}$ & Ampliar las facilidades para la venta online de & Agencias \\
distribución de las & & Viajes \\
ofertas del destino & Incluir en los canales de venta online las ofertas & Agencias \\
& & $\begin{array}{l}\text { de alojamientos y servicios de restauración del } \\
\text { sector no estatal. }\end{array}$ & Hojes \\
& & \\
Incrementar el uso & Realizar una evaluación y perfeccionamiento de & INFOTUR \\
de Internet & para los contenidos a publicitar sobre el destino Holguín \\
publicitar & los turístico Holguín, considerando las preferencias & \\
atractivos & del de este mercado. & \\
destino & &
\end{tabular}

\begin{tabular}{lll}
\hline Estrategia & Acción & Responsable
\end{tabular}

Aumentar las publicaciones del destino en INFOTUR

Facebook. Holguín

Gestionar la reputación online del destino Holguín INFOTUR en TripAvisor, redes sociales y otros sitios de Holguín comentarios

Diversificar las Ampliar ofertas de paquetes que combinen Agencias de ofertas del destino alojamientos en playa con excursiones a senderos, Viajes de incluyendo parques naturales y ciudades patrimoniales. Holguín actividades que satisfagan los Diseñar excursiones temáticas a la medida para Agencias de motivos de viajes clientes que prefieran disfrutar de la cultura local Viajes o la naturaleza. Holguín

Tabla 3. Propuesta de estrategias y acciones para mejorar la gestión del destino Holguín en el mercado cubano.

\begin{tabular}{llll}
\hline Estrategias & Acciones & Responsable \\
& & \\
\hline Ampliar la cartera & Aprovechar la existencia de sitios naturales Agencias de \\
de productos del atractivos, cercanos a los hoteles de playa, para Viajes & de \\
destino, & incorporar oferta de excursiones económicas que Holguín & \\
incorporando & permitan disfrutar de los mismos. &
\end{tabular}


ofertas específicas Incorporar ofertas de paquetes económicos de dos Agencias de que satisfagan las noches en hoteles de sol y playa con opción de Viajes de preferencias del

Holguín mercado nacional.

\begin{tabular}{lll}
\hline Estrategias & Acciones & Responsable
\end{tabular}

disfrutar adicionalmente de la visita a un sitio natural reconocido.

Ampliar en la Insertar información actualizada y atractiva en INFOTUR comunicación Facebook y YouTube. Holguín promocional online Mantener actualizada la información en los perfiles INFOTUR del destino la en las redes sociales del destino. Holguín atractivos y ofertas Gestionar la reputación online en sitios de INFOTUR de interés para el comentarios del mercado nacional. Holguín mercado nacional.

\section{Paso 7: propuesta de recomendaciones generales para favorecer la gestión sostenible de los mercados en el destino}

Después de analizar y proponer las estrategias y acciones para cada mercado se formularon recomendaciones generales para la gestión del conjunto de mercados del destino, las mismas se reflejan a continuación:

1. Innovar en el diseño y puesta en explotación de nuevos productos y ofertas en el destino Holguín, considerando los distintos segmentos de clientes y sus características y preferencias, en particular los intereses en los productos culturales, al evidenciarse que es una tendencia de la demanda que estará presente con mayor fuerza en los próximos años en los mercados que gestiona el destino Holguín.

2. Desarrollar ofertas a la medida

3. Incrementar las acciones online de comunicación promocional, abarcando fundamentalmente los sitios de comentario, plataformas y redes sociales de mayor utilización por los segmentos de mercado presentes en el destino y prestando especial interés a los contenidos de las publicaciones

4. Ampliar las facilidades de distribución online de todas las organizaciones que oferten productos y servicios de interés para los turistas que visitan el destino Holguín

5. Establecer una alianza estratégica entre las agencias de viaje del destino e INFOTUR para realizar una gestión de mercados coherente, atendiendo al protagonismo de ambos en este ámbito. 


\section{Conclusiones}

Como resultado de la investigación se concluye que:

1. El destino turístico Holguín posee gran dependencia de un pequeño número de mercados, principalmente de Canadá con más del 40 por ciento de la operación

2. Los principales mercados del destino Holguín tienen marcada preferencia por el sol y la playa, pero se prevé una tendencia a demandar, cada vez más, ofertas relacionadas con la cultura y la naturaleza

3. Es necesario mejorar la gestión de mercados en el destino Holguín en lo referido a: innovación en el diseño de productos y ofertas, perfeccionamiento de la comunicación promocional del destino, en particular en los canales online y diversificación de los canales de distribución de las ofertas del destino

4. INFOTUR y las agencias de viajes del destino Holguín tienen un papel relevante en el perfeccionamiento de la gestión de mercados del destino

5. La propuesta de estrategias y acciones realizada para los principales mercados; así como las recomendaciones generales para la gestión del destino favorecen el desarrollo turístico sostenible del destino Holguín.

\section{Referencias bibliográficas}

ANALYTICA República Dominicana. (2019). Inteligencia económica y estrategia. Disponible en https://www.analytica.com.do/2018/07/llegada-de-turistas-a-repdom/

DATATUR (2020). Análisis integral de turismo México, disponible en datatur.sectur.gob.mx/SitePages/

EOEI. (2018). doi:http://www.portal.euromonitor.com/portal/analysis/tab

Gabriela \& María. (2016). EL DESARROLLO TURÍSTICO SOSTENIBLE. Tren Crucero del Ecuador. Estudios y Perspectivas en Turismo, 25(1),57-72. [fecha de Consulta 2 de marzo de 2020]. ISSN: 0327-5841. Disponible en: https://www.redalyc.org/articulo.oa?id=1807/180743275004

Hernández-Martín, R. (2006). Los mercados turísticos. Researchgate.

López-Bonilla, J. M., \& López, L. (2015). Manual de investigación de mercados turísticos. Researchgate.

Monge, J., \& Yague Perales, R. (2016). EL DESARROLlO TURÍSTICO SOSTENIBLE. Tren Crucero del Ecuador. Estudios y Perspectivas en Turismo, 25(1),57-72.

Disponible

en: https://www.redalyc.org/articulo.oa?id=1807/180743275004 
OMT. (2019). Resultados del turismo internacional 2018 y perspectivas 2019.

ONEI. (2016). Anuario Estadístico de Cuba, disponible en https://www.directoriocubano.info/cuba/la-oficina-nacional-de-estadisticas-einformacion-onei-d-cuba-presenta-su-edicion-2016/

ONEI. (2017). Anuario Estadístico de Cuba, disponible en https://www.directoriocubano.info/cuba/la-oficina-nacional-de-estadisticas-einformacion-onei-de-cuba-presenta-su-edicion-2017/

ONEI. (2018). Anuario Estadístico de Cuba, disponible en https://www.directoriocubano.info/cuba/la-oficina-nacional-de-estadisticas-einformacion-onei-de-cuba-presenta-su-edicion-2018/

ONEI. (2019). Anuario Estadístico de Cuba, disponible en https://www.directoriocubano.info/cuba/la-oficina-nacional-de-estadisticas-einformacion-onei-de-cuba-presenta-su-edicion-2019/

Osorio García, M., Ramírez de la O, I. L., \& Viesca González, C. (2018). Tendencias del turismo hasta 2030. Contrastes entre lo internacional y lo nacional Universidad Autónoma del Estado de México,

Pololikashvili, Z. (2020). Presentación Barómetro OMT

UNEP , \& UNWTO. (2005). Making Tourism More Sustainable - A Guide for Policy Makers.

\section{$\lfloor$ Ciencia}




\section{PARA CITAR EL ARTÍCULO INDEXADO.}

Medina Labrada, J. R., Clarke Bloomfield, M., \& Pérez Ricardo, E. del C. (2021). Gestión de mercados en el destino Holguín para favorecer un desarrollo turístico sostenible. Explorador Digital, 5(1), 103-120. https://doi.org/10.33262/exploradordigital.v5i1.1492

\section{¿Ciencia}

El artículo que se publica es de exclusiva responsabilidad de los autores y no necesariamente reflejan el pensamiento de la Revista Explorador Digital.

El artículo queda en propiedad de la revista y, por tanto, su publicación parcial y/o total en otro medio tiene que ser autorizado por el director de la Revista Explorador Digital.
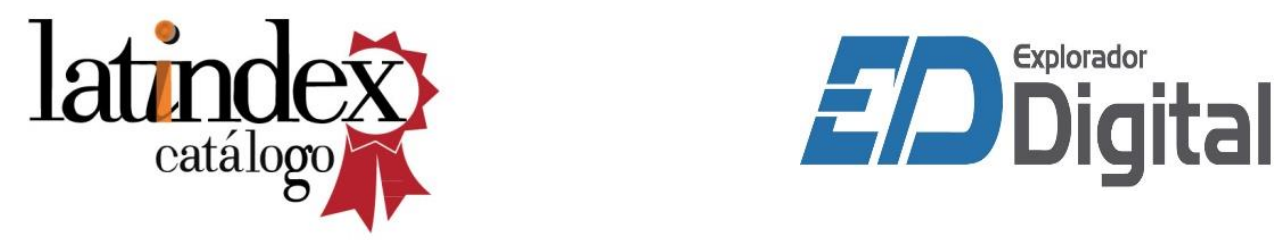